\title{
Sevoflurane sedation in a rat model of sepsis: systemic and neuro-inflammation
}

Schläpfer $M^{1}$, 2, Baumann $L^{2}$, Eugster $\mathrm{P}^{1}$, Hasler $\mathbf{M}^{1}$, Booy $C^{2}$, Beck-Schimmer B $^{1,2,3}$

1 Institute of Anesthesiology, University Hospital Zurich, Zurich, Switzerland

2 Institute of Physiology, University Zurich Irchel, Zurich, Switzerland

${ }^{3}$ Department of Anesthesiology, University of Illinois at Chicago, Chicago, IL, USA

\section{Background}

Volatile anesthetics such as sevoflurane have shown anti-inflammatory properties in various organs and settings [1]. We were interested in evaluating the safety profile and the potential of sevoflurane to reduce neuroinflammation in sepsis.

\section{Methods}

Adult male Wistar rats $(329 \pm 21 \mathrm{~g})$ were subjected to intravenous injection of $1 \mathrm{mg} / \mathrm{kg}$ lipopolysaccharides (LPS) or sham procedure (phosphate-buffered saline, PBS) and randomly assigned to sedation with propofol or sevoflurane for $12 \mathrm{~h}$. Blood samples were taken every 3 hours. The inflammatory mediators cytokine-induced neutrophil chemoattractant protein-1 (CINC-1) and monocyte chemotactic protein-1 (MCP-1) were evaluated in serum and brain tissue. Brain damage marker mRNA s100B, transforming growth factor $\beta$ (TGF- $\beta$ ) and glial fibrillary acidic protein (GFAP) as well as wet-to-dry ratio were assessed. Statistical analysis was performed using one way analysis of variance, $\mathrm{p}<0.05$ was considered significant.

\section{Results}

There was no difference with regard to ventilation or mean arterial blood pressure in the two sedation groups. Pro-inflammatory cytokines in serum were upregulated with two peaks at $3 \mathrm{~h}$ and at $12 \mathrm{~h}$ in the propofol and sevoflurane sepsis group (12h CINC1: $401 \pm 305$ vs $96 \pm 44 \mathrm{ng} / \mathrm{ml} ; 12 \mathrm{~h} \mathrm{MCP}-14.82 \pm 1.92$ vs. $2.51 \pm 0.54 \mu \mathrm{g} / \mathrm{ml}$; both $\mathrm{p}<0.001)$, values were higher in the propofol compared to the sevoflurane group. (Fig. 1A and Fig. 1D)

Also in brain tissue CINC-1 and MCP-1 protein was increased upon LPS injection, however, with similar values in both sedation groups. (Fig. 1C and Fig. 1F)

Brain damage marker mRNA s100B, TGF- $\beta$ and GFAP were decreased by $2 \%$, by $25 \%$ and increased by $43 \%$ by sevoflurane, but without reaching statistical significance $(p=0.99,0.35$ and 0.42, Fig. 2B-D).

Wet to dry ratio was not affected by the sedative regimen in septic animals (4.89 \pm 0.07 vs. $4.80 \pm 0.07$, $\mathrm{p}=0.23$, Fig. 2A).
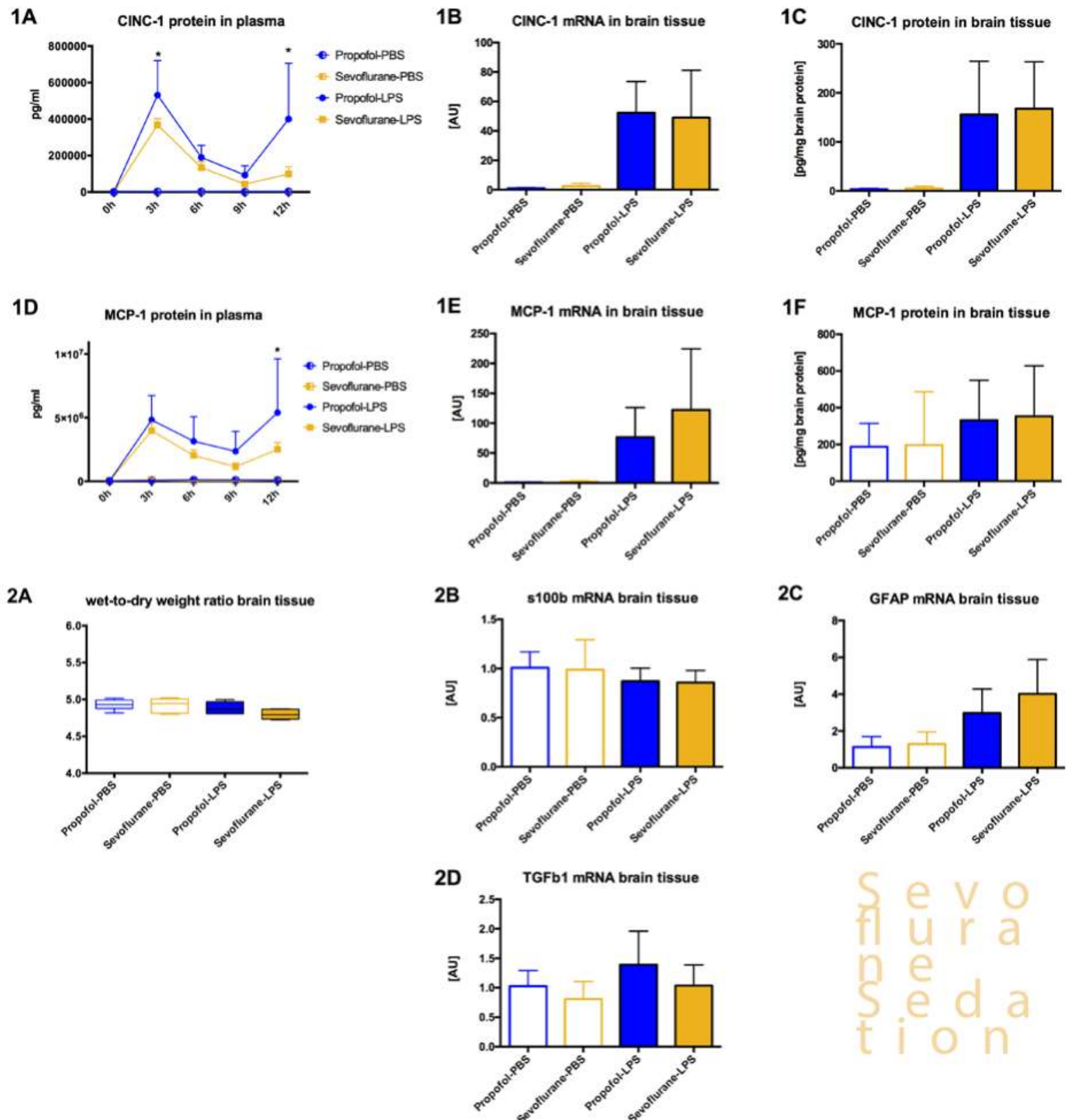

\section{Conclusion}

Sevoflurane seems to be safe in a rat sepsis model with regard to neuro-inflammation and offering the benefit of attenuating the systemic inflammatory reaction. 